Craig W. Reid MD, Raymond J. Martineau MD, Donald R. Miller MD, Kathryn A. Hull RN, John Baines BSc, Patrick J. Sullivan MD

\title{
A comparison of transcutaneous, end-tidal and arterial measurements of carbon dioxide during general anaesthesia
}

A randomized, prospective study was performed to evaluate the accuracy of a new transcutaneous carbon dioxide $\left(\mathrm{CO}_{2}\right)$ monitor (Fastrac during general anaesthesia. Twenty-two adult patients undergoing elective surgery were subjected to three different levels of minute ventilation by varying their respiratory rates in a randomized cross-over design. Simulianeous measurements of transcutaneous $\mathrm{CO}_{2}\left(\mathrm{PTCCO}_{2}\right)$ and arterial $\mathrm{CO}_{2}$ $\left(\mathrm{PaCO}_{2}\right)$ were obtained at three levels of minute ventilation (low, medium and high). End-ridal $\mathrm{CO}_{2}\left(\mathrm{PtCCO}_{2}\right)$ values were also recorded from a mass spectrometer (SARA $\$$ ) at each time period. A total of 66 data sets with $\mathrm{PaCO}_{2}$ ranging from $28-62$ mmHg were analyzed. The PrcCO values demonstrated a high degree of correlation with $\mathrm{PaCO}_{2}$ over the range of minute ventilation $(y=0.904 x+6.36, r=0.92, P<0.001)$. The $\mathrm{PErCO}_{2}$ measurement also demonstrated a generally good correlation with $\mathrm{PaCO}_{2}(y=0.62 x+9.21, r=0.89$, and $P<$ 0.01 ). However, the $\mathrm{P}_{5 T} \mathrm{CO}_{2}-\mathrm{PaCO}_{2}$ gradients (mean $7.0 \pm 3.1$ $\mathrm{mmHg}$ ) were greater than the $\mathrm{PrCCO}_{2}-\mathrm{PaCO}_{2}$ gradients (mean

\section{Key words}

CARBON DIOXIDE: monitoring;

TENSION: arterial, cutaneous, end-tidal, gradients; MONITORING: carbon dioxide;

VENTILATION: carbon dioxide tension.

From the Departments of Anaesthesia and Biomedical Engineering. Ottawa General Hospital and The University of Ottawa, Ottawa, Ontario.

Presented at the Annual Meeting of The Canadian Anaesthetists' Society, Vancouver, June, 1990.

Supported in part by a research grant from Johnson and Johnson (Medical Products) Inc.

Address correspondence to: Dr. Donald R. Miller, Department of Anaesthesia, Ottawa General Hospital, 501 Smyth Road, Ottawa, Ontario KIH 8L6.

Accepted for publication 29th August, 1991.
$2.3 \pm 2.4 \mathrm{mmHg}$ ) at all three levels of minute ventilation $(P<$ 0.05). These differences were greatest when $\mathrm{PaCO}_{2}$ was in the high range (48-60 $\mathrm{mm} \mathrm{Hg}$ ). We conclude that the new Fastrac $\mathrm{CO}_{2}$ monitor is accurate for monitoring carbon dioxide levels during general anaesthesia. The new transcutaneous devices provide an effective method for non-invasive monitoring of $\mathrm{CO}_{2}$ in situations where continuous, precise control of $\mathrm{CO}_{2}$ levels is desired.

Une étude prospective randomisée fut entreprise afin d'évaluer durant l'anesthésie générale un nouveau moniteur transcutané de $\mathrm{CO}_{2}$ (Fastrac ${ }^{(\pi)}$ ). Vingt-deux patients adultes subissant une chirurgie élective ont subi trois différents niveaux de ventilation minute en variant la fréquence d'une façon randomisée avec entrecroisage. Les mesures simultanées de la $\mathrm{CO}_{2}$ transcutanée $\left(\mathrm{PTCCO}_{2}\right)$ et la $\mathrm{CO}_{2}$ artérielle $\left(\mathrm{PaCO}_{2}\right)$ furent obtenues à trois niveaux de ventilation minute (bas, moyen es élevé). Les valeurs de la $\mathrm{CO}_{2}$ en find'expiration $\left(\mathrm{PETCO}_{2}\right)$ furent aussi enregistrées par un spectromètre de masse (SARA à chaque période. Un total de 66 ensembles de données avec des $\mathrm{PaCO}_{2}$ variant de 28-62 $\mathrm{mmHg}$ furent analysées. Les valeurs de $\mathrm{PrCCO}_{2}$ ont démontré un haut degré de corrélation avec la $\mathrm{PaCO}_{2}$ pour ces valeurs de ventilation minute $(y=0,904 x+6,36, r=0,92, P$ $<0,001)$. Les mesures de la $\mathrm{PETCO}_{2}$ ont aussi démontré une bonne corrélation avec la $\mathrm{PaCO}_{2}(y=0,62 x+9,21, r=0,89$, et $\mathrm{P}<0.01$ ). Cependant, les gradients de $\mathrm{PtrCO}_{2}-\mathrm{PaCO}_{2}$ (moyenne 7,0 $\pm 3,1 \mathrm{mmHg}$ ) furent plus grands que les gradients de $\mathrm{PrCCO}_{2}-\mathrm{PaCO}_{2}$ (moyenne 2,3 $\pm 2,4 \mathrm{mmHg}$ ) aux trois valeurs de ventilation minute étudiées $(P<0,05)$. Ces différences étaient plus élevées quand la $\mathrm{PaCO}_{2}$ était maintenue à des niveaux élevés (48-60 $\mathrm{mmHg}$ ). On conclut que le nouveau moniteur de $\mathrm{CO}_{2}$ Fastrac est précis pour la surveillance du niveau du $\mathrm{CO}_{2}$ durant l'anesthésie générale. Ces nouveaux appareils transcutanés fournissent une méthode efficace pour la surveillance non-invasive de la $\mathrm{CO}_{2}$ dans des situations où un contrôle continu et précis du niveau de $\mathrm{CO}_{2}$ est désiré. 
In order to monitor the adequacy of alveolar ventilation, it is now standard practice to have a continuous estimate of arterial carbon dioxide $\left(\mathrm{PaCO}_{2}\right)$ for all patients undergoing general anaesthesia. Continuous measurement of end-tidal carbon dioxide partial pressure $\left(\mathrm{PETCO}_{2}\right)$ by either mass spectrometry or infrared capnometry has become the most widely used method for measuring $\mathrm{CO}_{2}$ concentrations of the end-tidal respiratory gases. The $\mathrm{PETCO}_{2}$ is used to reflect arterial $\mathrm{PaCO}_{2}$ levels, assuming a normal $\mathrm{PETCO}_{2}-$ $\mathrm{PaCO}_{2}$ gradient. ${ }^{\mathrm{l}}{ }^{-3}$ However, this method of estimating arterial $\mathrm{PaCO}_{2}$ is sometimes inaccurate in clinical practice, as a result of influences by pathologic processes which increase the $\mathrm{PETCO}_{2}-\mathrm{PaCO}_{2}$ gradient. This includes diseases which increase pulmonary dead space, and to a lesser extent, diseases which cause ventilation-perfusion mismatching or pulmonary shunting. ${ }^{4-6}$ This concern prompted the current investigators to evaluate the accuracy of a new transcutaneous carbon dioxide $\left(\mathrm{PETCO}_{2}\right)$ monitor with a dual sensing electrode, as an additional method of $\mathrm{CO}_{2}$ measurement.

Recent technological advances have led to the development of several $\mathrm{PrCCO}_{2}$ monitors which are considerably smaller and easier to operate than the early prototypes. Additional advances include improved calibration, and the development of a dual sensing electrode which can measure oxygen and carbon dioxide levels simultaneously. The transcutaneous monitor provides an estimate of $\mathrm{PaCO}_{2}$ by non-invasive sampling from "arterialized" capillary blood, a process which is not influenced by abnormalities in pulmonary gas exchange. ${ }^{7.8}$ The transcutaneous $\mathrm{CO}_{2}$ monitor may therefore provide a closer approximation of $\mathrm{PaCO}_{2}$ than does capnography.

The purpose of this prospective, randomized study was to examine the potential clinical utility of $\mathrm{PTCCO}_{2}$ monitoring during general anaesthesia by evaluating the accuracy of the most recently commercially available transcutaneous monitor (Fastrac(i\$). A secondary aim was to compare transcutaneous-arterial and end-tidal-arterial $\mathrm{CO}_{2}$ gradients at different levels of minute ventilation. A healthy patient population was selected for this initial validation.

\section{Methods}

\section{Patient population}

Twenty-two ASA physical status I or II patients who were scheduled to undergo elective surgery under general anaesthesia in the supine position were enrolled in the study. All patients gave written, informed consent to the protocol which had been approved by the Hospital Human Experimental Procedures Committee. Excluded were patients greater than $60 \mathrm{yr}$ of age, those with a history of smoking more than ten pack-years, asthmatics, individuals with COPD, and patients who were either obese or pregnant.

\section{Anaesthetic management}

Patients received premedication with oral diazepam, 0.15 $\mathrm{mg} \cdot \mathrm{kg}^{-1}$ given $90 \mathrm{~min}$ preoperatively. In the operating room, intravenous access was established, and an ECG, non-invasive blood pressure monitor, and pulse oximeter were applied. Induction of anaesthesia was performed with fentanyl 2-4 $\mu \mathrm{g} \cdot \mathrm{kg}^{-1}$, thiopentone $4-5 \mathrm{mg} \cdot \mathrm{kg}^{-1}$ and an appropriate muscle relaxant. Following tracheal intubation, inspired and end-tidal concentrations of oxygen, carbon dioxide, and anaesthetic gases were monitored with an online mass spectrometer (SARA, PPG). Maintenance of anaesthesia consisted of nitrous oxide and oxygen in a 2:1 ratio, isoflurane ( $0.25-1.5 \%$ end-tidal), and incremental boluses of either fentanyl or alfentanil as required to maintain an appropriate depth of anaesthesia, as determined by the attending staff physician. Upon completion of surgery, inhalational agents were discontinued, residual neuromuscular blockade was reversed, and extubation was performed after patients had been breathing $100 \%$ oxygen for several minutes.

\section{Protocol}

The lungs were mechanically ventilated with a tidal volume of $8-10 \mathrm{ml} \cdot \mathrm{kg}^{-1}$ and a total fresh gas flow rate (FGF) of $3.0 \mathrm{~L} \cdot \mathrm{min}^{-1}$, delivered from a circle breathing system with a carbon dioxide absorber. Once a stable level of anaesthesia had been achieved, each patient was subjected to three different levels of minute ventilation in a randomized cross-over design. Minute ventilation was adjusted by varying the respiratory frequency, while tidal volume and FGF remained constant. This allowed for simultaneous measurements of $\mathrm{PTCCO}_{2}$ and PETCO $\mathrm{CO}_{2}$ to be compared with $\mathrm{PaCO}_{2}$ over a range of carbon dioxide values, while each patient served as his or her own control. At each level of minute ventilation, the following end-tidal $\mathrm{CO}_{2}$ values were achieved:

$$
\begin{aligned}
& \text { Low - } \begin{array}{l}
\text { PETCO } \\
2
\end{array} 28-30 \mathrm{mmHg} \\
& \text { Medium - } \mathrm{PETCO}_{2} 34-36 \mathrm{mmHg} \\
& \text { High - } \mathrm{PETCO}_{2} 40-42 \mathrm{mmHg}
\end{aligned}
$$

\section{Measurements}

Heart rate (HR) and mean arterial pressure (MAP) were measured using a Dinamapp 1846 SXP non-invasive monitor. Oxygen saturation was recorded from a pulse oximeter, and temperature was measured using a nasopharyngeal temperature probe.

Transcutaneous $\mathrm{CO}_{2}\left(\mathrm{PTCCO}_{2}\right)$ measurements were recorded from the digital display of the Fastrac ${ } \mathrm{PTCCO}_{2}$ monitor. Before each study, the device was calibrated 
TABLE I Demographic data

\begin{tabular}{ll}
\hline Patients $(n)$ & 22 \\
Age $(\mathrm{yr})$ & $37.2 \pm 11.0$ \\
Sex $(\mathrm{m} / \mathrm{f})$ & $5 / 17$ \\
Weight $(\mathrm{kg})$ & $65.1 \pm 11.2$ \\
ASA $(\mathrm{I} / \mathrm{II} / \mathrm{III})$ & $14 / 6 / 2$ \\
\hline
\end{tabular}

TABLE II Haemodynamic and temperature values (mean \pm SD)

\begin{tabular}{lrrr}
\hline & \multicolumn{1}{c}{ Low } & \multicolumn{1}{c}{ Medium } & \multicolumn{1}{l}{ High } \\
\hline & & & \\
$\mathrm{HR}\left(\mathrm{min}^{-1}\right)$ & $69 \pm 14$ & $69 \pm 13$ & $70 \pm 13$ \\
$\mathrm{MAP}(\mathrm{mmHg})$ & $85 \pm 13$ & $87 \pm 12$ & $87 \pm 12$ \\
$\mathrm{SaO}{ }_{2}(\%)$ & $98.7 \pm 0.8$ & $98.7 \pm 0.9$ & $98.5 \pm 0.8$ \\
Temperature $\left({ }^{\circ} \mathrm{C}\right)$ & $35.5 \pm 0.4$ & $35.5 \pm 0.4$ & $35.5 \pm 0.4$ \\
\hline
\end{tabular}

Heart rate (HR), mean anterial pressure (MAP), oxygen saturation $\left(\mathrm{SaO}_{2}\right)$ and nasopharyngeal temperature for the three ranges of minute ventilation. Low $=$ PETCO $_{2} 28-30 \mathrm{mmHg}$, Medium $=\mathrm{PETCO}_{2} 34-36$ $\mathrm{mmHg}$. $\mathrm{High}=\mathrm{PETCO}_{2} 40-42 \mathrm{mmHg}$.

using a two-point self-calibration. The monitoring technique was standardized by applying a $2.5 \mathrm{~cm}$ probe to the patient's anterior chest. The probe was heated to $41^{\circ} \mathrm{C}$ to "arterialize" the skin capillary blood flow, and the monitor used an internal algorithm to compensate for the effects of the heated probe on $\mathrm{CO}_{2}$ tension.

End-tidal $\mathrm{CO}_{2}\left(\mathrm{PETCO}_{2}\right)$ measurements were recorded from the on-line display of a mass spectrometer (System for Anesthetic and Respiratory Analysis ${ }^{\mathbb{W}}$, PPC, Missouri), using continuous sampling from a connector attached to the proximal end of the endotracheal tube. The mass spectrometer automatically performed a self-calibration every three hours using a guaranteed reference cylinder containing $5.1 \% \mathrm{CO}_{2}$ and $60 \% \mathrm{~N}_{2} \mathrm{O}$. Carbon dioxide and $\mathrm{N}_{2} \mathrm{O}$ were "read" at mass charge ratios of 12 and 30 respectively, to prevent interference resulting from the identical molecular weights of these two gases. Using this system, the end-tidal $\mathrm{CO}_{2}$ was determined from the latter portion of two successive respiratory waveforms. The capnograms were displayed on "Amber" monitors, and the measurements were recorded only when the $\mathrm{CO}_{2}$ waveforms were normal.

Arterial $\mathrm{CO}_{2}$ values were measured from blood gas samples obtained by radial artery puncture, and analyzed with a Corning 178 apparatus, which was calibrated each morning using a commercially available quality control blood gas analyzer (Ciba-Corning). Simultaneous measurements of $\mathrm{PTCCO}_{2}, \mathrm{PETCO}$ and $\mathrm{PaCO}_{2}$ were recorded at each successive $\mathrm{PETCO}_{2}$ level during maintenance of anaesthesia. Following each adjustment of ventilatory rate, five to ten minutes were allowed for stabilization of $\mathrm{PETCO}_{2}$ and measurements were not recorded for an additional ten minutes to ensure that both $\mathrm{PTCO}_{2}$ and PETCO${ }_{2}$ values had equilibrated at the new level of minute ventilation.

\section{Statistical analysis}

Linear regression analysis was performed to determine the correlation between each non-invasive method of $\mathrm{CO}_{2}$ measurement and the arterial $\mathrm{CO}_{2}$ over the entire range of carbon dioxide values. Student's unpaired t tests were also used to compare the $\mathrm{PrCCO}_{2}-\mathrm{PaCO}_{2}$ and $\mathrm{PETCO}_{2}-\mathrm{PaCO}_{2}$ gradients at each level of minute ventilation. Values are expressed as ranges and mean $\pm S D$ in the figures and text, with statistical significance assumed when $P<0.05$.

\section{Results}

Twenty-two patients completed the study protocol, and the demographic data are shown in Table 1. Surgical procedures included orthopaedic $(n=1)$, general surgery $(n=7)$, urological $(n=3)$ and gynaecological operations $(n=11)$, which had an average anaesthetic time of $2.1 \pm$ $0.3 \mathrm{hr}$ (range $=1.0-5.4 \mathrm{hr}$ ). The tracheas of all but two patients were extubated upon termination of surgery, and all patients recovered uneventfully.

Sixty-six data sets consisting of simultaneous measurements of $\mathrm{PTCCO}_{2}, \mathrm{PETCO}_{2}$ and $\mathrm{PaCO}_{2}$ were obtained. In nine patients, a third set of measurements could not be completed due to termination of the surgical procedure prior to equilibration of $\mathrm{CO}_{2}$ at the last step change in minute ventilation. The data sets were equally distributed amongst the three levels of minute ventilation. Heart rate, mean arterial pressure, and oxygen saturation were similiar at the three measurement periods (Table II). Nasopharyngeal temperatures, which ranged from $34.8-36.3^{\circ} \mathrm{C}$ were also not different throughout the study period. The largest single decrease in temperature for any one patient was $0.5^{\circ} \mathrm{C}$ during the period of observation.

The relation of $\mathrm{PrCCO}_{2}$ and $\mathrm{PETCO}_{2}$ with respect to $\mathrm{PaCO}_{2}$ values at all levels of minute ventilation is displayed in the scattergrams of Figures $I$ and 2. The $\mathrm{PTCCO}_{2}$ measurements tended to be slightly greater than the arterial $\mathrm{CO}_{2}$ values, but correlated very closely with $\mathrm{PaCO}_{2}$ as defined by the relationship $y=0.904 x+6.36$ with a correlation coefficient of $0.92, P<0.00$ l (Figure 1). The PETCO , which tended to underestimate the arterial $\mathrm{CO}_{2}$, values, also showed a generally good correlation with $\mathrm{PaCO}_{2}$ according to the relationship $\mathrm{y}=0.62 \mathrm{x}+9.21$, with a correlation coefficient of $0.89, P<0.01$ (Figure 2).

The mean transcutaneous, end-tidal and arterial $\mathrm{CO}_{2}$ values corresponding to the low, medium and high levels of minute ventilation are presented in Table III. From this data, the $\mathrm{PTCCO}_{2}-\mathrm{PaCO}_{2}$ and $\mathrm{PETCO} 2-\mathrm{PaCO}_{2}$ gradients were calculated, as displayed in Figure 3. This figure demonstrates that the $\mathrm{PETCO}_{2}-\mathrm{PaCO}_{2}$ gradients were larger 


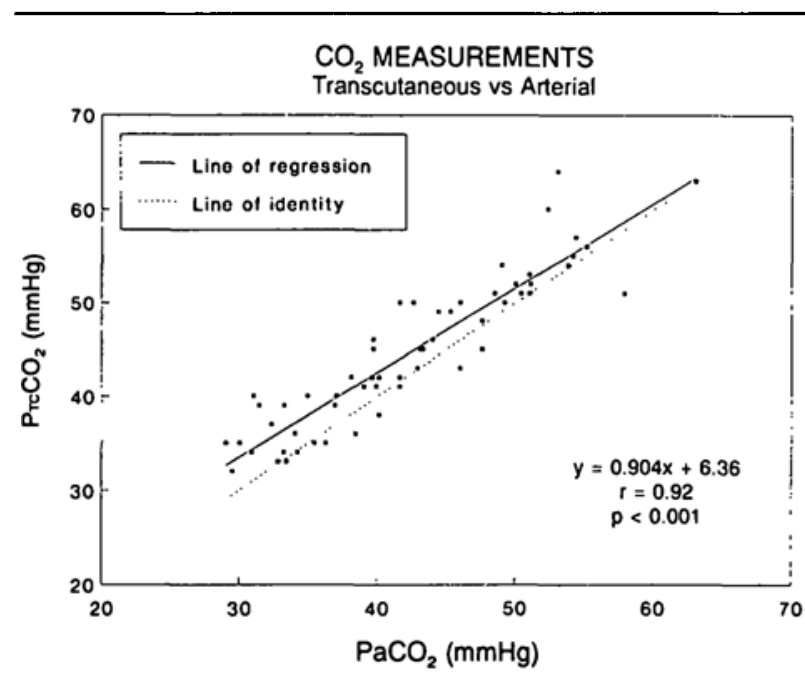

FIGURE I Transcutancous $\mathrm{CO}_{2}\left(\mathrm{PTCCO}_{2}\right)$ vs arterial $\mathrm{CO}_{2}\left(\mathrm{PaCO}_{2}\right)$ measurements over the entire range of minute ventilation.

TABLE III $\mathrm{CO}_{2}$ values for the three levels of minute ventilation (mean $\pm S D)$

\begin{tabular}{llll}
\hline & Low & Medium & High \\
\hline $\mathrm{PTCCO}_{2}(\mathrm{mmHg})$ & $36.2 \pm 3.9$ & $46.3 \pm 3.8$ & $53.2 \pm 5.0$ \\
$\mathrm{PETCO}_{2}(\mathrm{mmHg})$ & $28.2 \pm 1.1$ & $34.9 \pm 1.2$ & $42.1 \pm 1.4$ \\
$\mathrm{PaCO}_{2}(\mathrm{mmHg})$ & $33.5 \pm 4.3$ & $41.3 \pm 3.2$ & $51.3 \pm 4.8$ \\
\hline
\end{tabular}

The mean $\pm \mathrm{SD}$ transcutaneous $\left(\mathrm{PTCCO}_{2}\right)$, end-tidal $\left(\mathrm{PETCO}_{2}\right)$ and arterial $\left(\mathrm{PaCO}_{2}\right)$ carbon dioxide values for the three levels of minute ventilation (refer to legend of Table II for abbreviations).

than the $\mathrm{PTCCO}_{2}-\mathrm{PaCO}_{2}$ gradients at all three levels of minute ventilation $(P<0.05)$, with the end-tidal arterial gradient being largest at the high $\mathrm{CO}_{2}$ levels $(P<0.001)$. Intraoperatively, the mean $\mathrm{PTCCO}_{2}-\mathrm{PaCO}_{2}$ gradient was only $2.3 \pm 2.4 \mathrm{mmHg}$ (range $=0.5-11.0 \mathrm{mmHg}$ ), while the mean $\mathrm{PETCO}_{2}-\mathrm{PaCO}_{2}$ gradient averaged $7.0 \pm 3.1$ $\mathrm{mmHg}$ (range $=2.0-21.0 \mathrm{mmHg}$ ).

\section{Discussion}

Continuous measurement of end-tidal carbon dioxide $\left(\mathrm{PETCO}_{2}\right)$ by either mass spectrometry or infrared capnometry has become standard practice for monitoring $\mathrm{CO}_{2}$ concentrations of the end-tidal respiratory gases during general anaesthesia. However, one limitation of capnometry is an uncertainty of the magnitude of the end-tidal to arterial $\mathrm{CO}_{2}$ gradient, which can vary between individuals. Most importantly, diseases which increase alveolar dead space will increase the end-tidal to arterial $\mathrm{CO}_{2}$ gradient. ${ }^{4,699}$ It has also been shown that during anaesthesia and mechanical ventilation the $\mathrm{PETCO}_{2}-\mathrm{PaCO}_{2}$ gradient can be markedly increased even in individuals who deny any history of respiratory symptoms. ${ }^{10}$ This concern

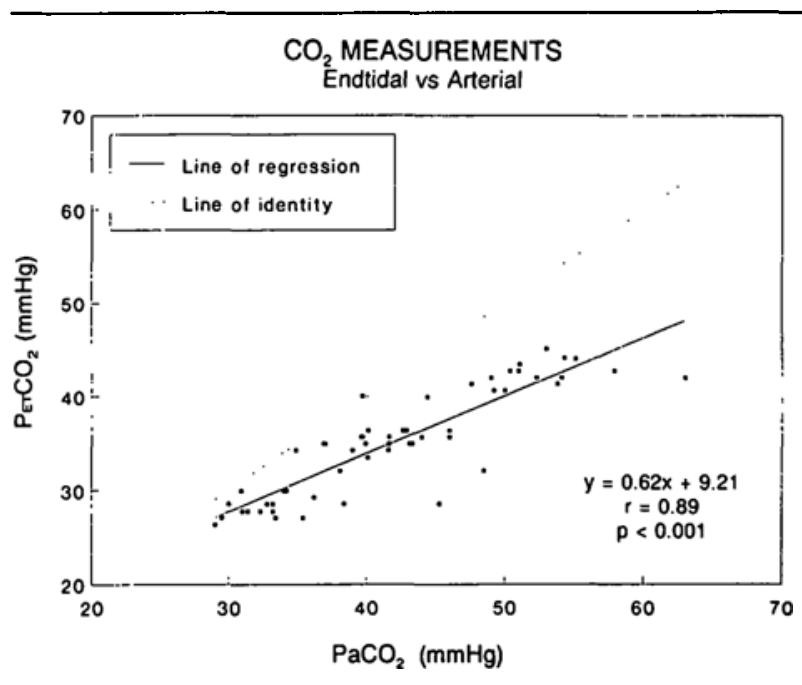

FIGURE 2 End-tidal $\mathrm{CO}_{2}\left(\mathrm{PeTCO}_{2}\right)$ vs arterial $\mathrm{CO}_{2}\left(\mathrm{PaCO}_{2}\right)$ measurements over the entire range of minute ventilation.

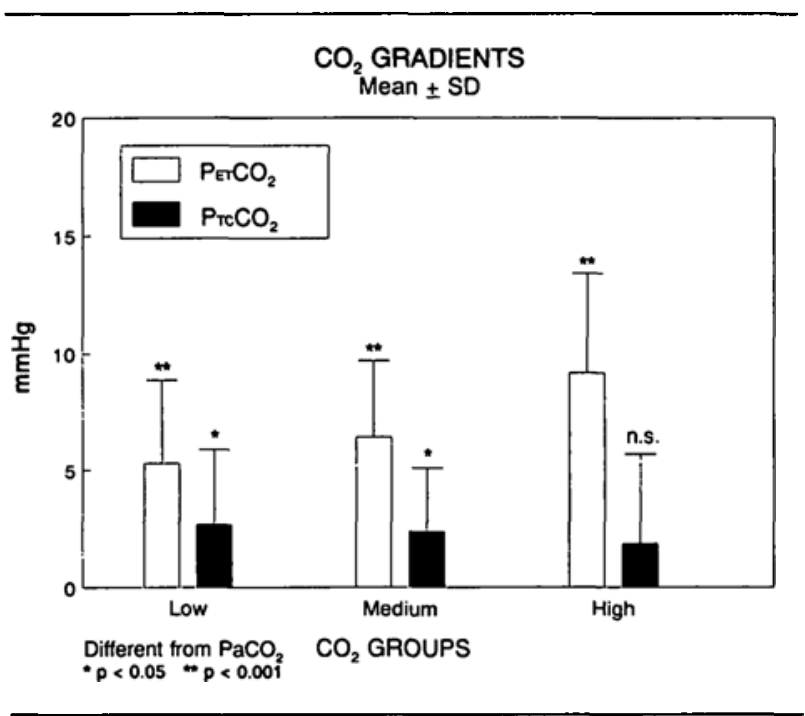

FIGURE 3 The $\mathrm{PTCCO}_{2}-\mathrm{PaCO}_{2}$ and $\mathrm{PETCO}_{2}-\mathrm{PaCO}_{2}$ gradients at low, medium and high levels of minute ventilation, respectively. The transcutaneous-arterial gradients of $\mathrm{CO}_{2}$ are consistently less than the end-tidal-anterial gradients $(P<0.05)$. For abbreviations refer to Iegend of Figure $\mathrm{I}$.

prompted us to evaluate a new transcutaneous $\mathrm{CO}_{2}$ monitoring device in adult patients whose lungs were mechanically ventilated, as $\mathrm{PrCCO}_{2}$ values are not influenced by factors which normally alter the end-tidal $\mathrm{CO}_{2}$ measurements.

Our results show that the new Fastrac $\mathrm{CO}_{2}$ monitor provides a good correlation with $\mathrm{PaCO}_{2}$ over a wide range of minute ventilation. The mean transcutaneous-arterial $\mathrm{CO}_{2}$ gradient with the Fastrac device was $2.3 \pm 2.4$ $\mathrm{mmHg}$, over a range of $0.5-11 \mathrm{mmHg}$. The monitor 
consistently provided a closer approximation to arterial $\mathrm{PaCO}_{2}$ than did capnography. This was especially so at the higher $\mathrm{PaCO}_{2}$ values, where the $\mathrm{PETCO}-\mathrm{PaCO}_{2}$ gradient was greatest. This observation is clinically important because it is in situations where carbon dioxide levels are rising that an accurate estimate of $\mathrm{PaCO}_{2}$ is most essential, due to detrimental effects of hypoventilation and the ensuing hypercarbia and respiratory acidosis. ${ }^{9}$

These findings are consistent with results obtained from evaluation of other transcutaneous $\mathrm{CO}_{2}$ monitors which have dual sensing electrodes (for carbon dioxide and oxygen). McEvedy et al. found that in neonates with severe lung disease, $\operatorname{PTCCO}_{2}$ (measured with a Kontron Microgas transcutaneous monitor) provides a more accurate reflection of $\mathrm{PaCO}_{2}(\mathrm{r}=0.76)$ than did $\mathrm{PETCO}_{2}$, as measured with the Puritan-Bennett Datex capnometer $(\mathrm{r}=0.39)$. " Others have shown that in neonates with respiratory distress syndrome, the Sensormedics cutaneous gas monitor provided a mean $\mathrm{PTCCO}_{2}-\mathrm{PaCO}_{2}$ gradient of $2.6 \pm 7.0 \mathrm{mmHg}$, compared with a $\mathrm{PETCO}_{2}-\mathrm{PaCO}_{2}$ gradient of $9.6 \pm 7.0 \mathrm{mmHg}$ (Beckmann respiratory gas analyzer). ${ }^{12}$ Another recent investigation in adults compared transcutaneous and end-tidal measurements of $\mathrm{CO}_{2}$ during weaning from mechanical ventilation. In the study, Healey et al. demonstrated a $2.4 \pm 5.7 \mathrm{mmHg}$ PTCCO $-\mathrm{PaCO}_{2}$ gradient with a TCM-20 Radiometer $\mathrm{PTCCO}_{2}$ monitor, compared with a $7.5 \pm 5.6 \mathrm{mmHg}$ $\mathrm{PETCO}_{2}-\mathrm{PaCO}_{2}$ gradient when using the Lifespan 100 capnometer. $^{13}$

The results of our study may seem somewhat surprising with respect to the relationship of the end-tidal to arterial $\mathrm{CO}_{2}$ levels. The end-tidal values were less than arterial values by an average of $7 \mathrm{mmHg}$ - an end-tidal to arterial difference which is somewhat greater than the $3-5 \mathrm{mmHg}$ gradient usually reported for anaesthetized humans. ${ }^{2-4}$ As we had selected a healthy patient population for our study, we did not anticipate a $\mathrm{PETCO}_{2}-\mathrm{PaCO}_{2}$ gradient of this magnitude. However, it has been shown that the relationship between $\mathrm{PETCO}_{2}$ and $\mathrm{PaCO}_{2}$ is complex, and is actually determined by the slope of the "alveolar plateau" phase III of the $\mathrm{CO}_{2}$ single breath test, and not simply alveolar dead space. ${ }^{2} 4$ Thus, several factors in addition to the preoperative respiratory status of the patient will influence the observed intraoperative $\mathrm{CO}_{2}$ values. These include minute ventilation settings, the cardiovascular and volume status of the patient, and the effect of time. Raemer et al. showed that arterial to end-tidal $\mathrm{CO}_{2}$ differences actually vary considerably during anaesthesia, even in a given patient with stable vital signs. ${ }^{6}$ Two of his patients had negative arterial to end-tidal $\mathrm{CO}_{2}$ gradients, possibly due to the existence of areas of the lung with long time constants and a high $\mathrm{PaCO}_{2}{ }^{15}$ Another possible explanation for the $7.0 \mathrm{mmHg}$ PETCO$_{2}-\mathrm{PaCO}_{2}$ gradient we demonstrated was that although all our patients denied symptoms of respiratory disease, seven of the 22 subjects had smoked at some time in the past. Fletcher has shown that even in the absence of respiratory symptoms, smoking increases the end-tidal to $\mathrm{PaCO}_{2}$ difference during anaesthesia and artificial ventilation. ${ }^{\circ}$

Valid comparison of transcutaneous and end-tidal $\mathrm{CO}_{2}$ measurements must take into consideration the effect of temperature on measured $\mathrm{CO}_{2}$ values. In the current study, arterial blood gas samples were temperature-corrected to minimize the potential error related to differences between patients and within-patient temperature variation during the sampling periods. Temperature correction will produce a closer correlation of $\mathrm{PETCO}_{2}$ and $\mathrm{PaCO}_{2}$ values, but will increase the gradient between arterial and transcutaneous $\mathrm{CO}_{2}$ measurements. This is because the $\mathrm{PTCCO}_{2}$ monitor "arterializes" the capillary blood flow at the sensor site by heating the skin to $41^{\circ} \mathrm{C}$, and then corrects the measured $\mathrm{CO}_{2}$ value to $37^{\circ} \mathrm{C}$ rather than to the actual body temperature. Accordingly, the $\mathrm{PTCCO}_{2}-\mathrm{PaCO}_{2}$ gradient would be less than reported when using temperature-uncorrected arterial blood gas results, as has become common clinical practice. $^{16}$

This study did not address the issue of the possible influence of decreased tissue perfusion on the accuracy of the $\mathrm{PTCCO}_{2}$ monitor. In low cardiac output states, these devices may also have limitations, as does capnography, due to their dependence on local tissue perfusion. ${ }^{17}$ In such situations, it is probably best to rely on arterial blood gas sampling for accurate measurement of $\mathrm{CO}_{2}$ levels and acid-base status.

We do not wish to infer from our results that the new transcutaneous $\mathrm{CO}_{2}$ devices should replace capnography for routine respiratory monitoring in the perioperative setting. Limitations of this technology include the possibility of electrical drift of the signal, the requirement for regular maintenance and changes of the electrode membranes, and a small risk of thermal burns. There is no display of respiratory waveform. In contrast, capnography has the distinct advantage of providing a continuous $\mathrm{CO}_{2}$ trace, in addition to providing breath-by-breath measurement of $\mathrm{PETCO}_{2}$. The latter capability is crucial for allowing prompt verification of the correct position of the endotracheal tube, and for providing immediate warning of inadvertent disconnection from the ventilator.

Despite the limitations in transcutaneous $\mathrm{CO}_{2}$ monitoring, the newer transcutaneous $\mathrm{CO}_{2}$ devices may prove to be a valuable addition to capnography for patients who are suspected of having increased $\mathrm{PETCO}_{2}-\mathrm{PaCO}_{2}$ gradients, and in situations where continuous, non-invasive and precise control of the $\mathrm{CO}_{2}$ level is desired. Examples might include individuals who have intracranial hypertension and those patients undergoing intracranial surgery. 
The transcutaneous $\mathrm{CO}_{2}$ monitor may also be useful in the recovery room or intensive care unit for managing nonintubated patients in whom respiratory depression or respiratory failure is a potential problem. Transcutaneous $\mathrm{CO}_{2}$ monitoring may also be useful during weaning from mechanical ventilation, and may possibly facilitate a decrease in the number of arterial blood gas samples normally required in such situations. Finally, the newer monitors incorporate a pulse oximeter for measuring oxygen saturation.

This study evaluated the accuracy of a new transcutaneous carbon dioxide monitor for measuring $\mathrm{PrCCO}_{2}$ levels during general anaesthesia. The $\mathrm{PTCCO}_{2}$ values correlated very well with the measured $\mathrm{PaCO}_{2}$. Furthermore, the transcutaneous- $\mathrm{PaCO}_{2}$ gradients were consistently less than the end-tidal- $\mathrm{PaCO}_{2}$ gradients over a wide range of minute ventilation settings. The enhanced accuracy, non-invasiveness, and simplicity in calibration and operation of the new transcutaneous $\mathrm{CO}_{2}$ monitors may make these devices an important addition in the perioperative setting, particularly for patients who may have elevated $\mathrm{PETCO}_{2}-\mathrm{PaCO}_{2}$ gradients, and where continuous $\mathrm{CO}_{2}$ monitoring is desired for non-intubated patients.

\section{Acknowledgements}

The authors thank the anaesthetists, surgeons and nurses of the operating room of the Ottawa General Hospital, whose assistance and patience permitted these studies. The support of the inhalational therapy staff of our institution is also gratefully acknowledged.

\section{References}

1 Lillie PE, Roberts JG. Carbon dioxide monitoring. Anaesth Intensive Care 1988; 16: 41-4.

2 Nunn JF, Hill DW. Respiratory dead space and arterial to end-tidal $\mathrm{CO}_{2}$ tension difference in anaesthetized man. $\mathrm{J}$ Appl Physiol 1960; 15: 383-9.

3 Takki S, Aromaa $U$, Kauste $A$. The validity and usefulness of the end-tidal $\mathrm{pCO}_{2}$ during anacsthesia. Annals of Clinical Research 1972; 4: 278-84.

4 Whitesell $R$, Asiddao C. Gollman D et al. Relationship between arterial and peak expired carbon dioxide pressure during anaesthesia and factors influencing the difference. Anesth Analg 1981; 60: 508-12.

5 McAslan TC. Automated respiratory gas monitoring of critically injured patients. Crit Care Med 1976; 4: 255-60.

6 Raemer DB, Francis D, Philip JH. Variations in $\mathrm{PCO}_{2}$ between arterial and peak expired gas during anaesthesia. Anesth Analg 1983; 62: 1065-9.

7 Eberhard P. Mindt W. Schafer R. Cutaneous blood gas monitoring in the adult. Crit Care Med 1981; 9: 702-5.

8 Rafferty TD, Marrero $O$. Nardi $D$ et al. Relationship between transcutaneous and artcrial carbon dioxide ten- sion in adult patients anacsthetized with nitrous oxidefentanyl and nitrous oxide-enflurane. Anesth Analg 1981; 60: 504-7.

9 Nunn JF. Carbon dioxide. In: Nunn JF (Ed.). Applied Respiratory Physiology, 3rd cd, London: Butterworths Inc., 1987: 207-35.

10 Fletcher $R$. Smoking, age and the artifical end-tidal $\mathrm{PCO}_{2}$ difference during anacsthesia and controlled ventilation. Acta Anaesthiol Scand 1987; 31: 355-6.

11 McEvedy BA, McLeod ME, Mulera M, Kirpalini H, Lerman J. End-tidal, transcutaneous and arterial $\mathrm{PCO}_{2}$ measurements in critically ill neonates: a comparative study. Anesthesiology 1988; 69: 112-6.

12 Hand I, Shepard E, Krauss A, Auld P. Discrepancies between transcutaneous and end-tidal carbon dioxide monitoring in the critically ill neonate with respiratory distress syndrome. Crit Care Med 1989; 17: 556-9.

13 Healey C, Fedullo A, Swinburne J, Wahl G. Comparison of non-invasive measurements of carbon dioxide tension during withdrawal from mechanical ventilation. 1987; 15: 764-8.

14 Fletcher $R$, Johnson $B$. Deadspace and the single breath test for carbon dioxide during anaesthesia and artifical ventilation. $\mathrm{Br} J$ Anaesth 1984; 56: 109-19.

15 Fletcher $R$, Malmkoist G, Niklasson L, Jonson B. On-line measurement of gas exchange during cardiac surgery. Acta Anaesthiol Scand 1986; 30: 295-9.

16 Tinker JH, Campos JH. Pro: Blood gases should be corrected for temperature during hypothermic cardiopulmonary bypass: $\mathrm{pH}$ stat mode. Journal of Cardiothoracic Anaesthesia 1988; 2: 701-6.

17 Beran AV, Tolle CD. Huxtable RF. Cutaneous blood flow and its relationship to transcutaneous $\mathrm{O}_{2} / \mathrm{CO}_{2}$ measurements. Crit Care Med 1981; 9: 736-41. 